\title{
C reactive protein and prealbumin as markers of disease activity in shigellosis
}

\author{
W A Khan, M A Salam, M L Bennish
}

\begin{abstract}
To evaluate serum $C$ reactive protein (CRP) and prealbumin concentrations as markers of disease activity in shigellosis this study serially measured serum concentrations of CRP and prealbumin in 39 patients infected with Shigella spp, and a comparison group of 10 patients infected with Vibrio cholerae serotype 01 . On admission, patients with shigellosis had significantly higher median concentrations of CRP (109 $v 5 \mathrm{mg} / \mathrm{l} ; \mathrm{p}<0.01)$ and significantly lower median concentrations of prealbumin (16 v $23 \mathrm{mg} / \mathrm{dl} ; \mathrm{p}<0.01)$ than did patients with cholera. Among Shigella spp infected patients, CRP concentrations were significantly lower, and prealbumin concentrations significantly higher, on study days 3 and 5 when compared with admission values. Among Shigella spp infected patients, those in whom treatment failed had higher admission CRP concentrations than those in whom treatment was successful $(p=$ 0.142). An admission CRP concentration $\geqslant 110 \mathrm{mg} / \mathrm{l}$ had a $70 \%$ sensitivity and a $61 \%$ specificity in predicting failure of treatment among patients infected with Shigella spp; the predictive value of a positive and negative test was $14 \%$ and $96 \%$ respectively. In summary, acute shigellosis elicits an acute phase response, the magnitude of which predicts clinical outcome.
\end{abstract}

(Gut 1995; 37: 402-405)

Keywords: Shigella spp, dysentery, bacillary, Shigella dysenteriae type 1 , acute phase reactants, $\mathrm{C}$ reactive protein, prealbumin.

Clinical Sciences

Division, International

Centre for Diarrhoeal

Disease Research,

Dhaka, Bangladesh

W A Khan

M A Salam

Departments of

Pediatrics and

Medicine, New

England Medical

Center, Tufts

University School of

Medicine, Boston,

USA

M L Bennish

Correspondence to:

Dr W A Khan, ICDDR,B GPO Box 128, Dhaka 1000, Bangladesh.

Accepted for publication 18 January 1995
Shigellosis is a tissue invasive infection that elicits a pronounced inflammatory response at the site of primary infection in the colon. ${ }^{1-4}$ Although Shigella spp infections are usually associated with fewer and peripheral blood leucocytosis, ${ }^{5}$ information on other acute phase reactants during disease and recovery is limited.

Previous studies have found an inverse correlation between total serum protein concentration and the risk of death. ${ }^{6}$ It is possible that measurement of specific serum proteins, instead of determination of total serum protein, may provide an even more sensitive measure of the clinical course of Shigella spp infections. Determining changes in serum proteins could also provide insight into the nutritional disorders that occur during shigellosis. The nutritional consequences of shigellosis include an acute depression in serum protein concentrations, and growth interruption in children, ${ }^{78}$ effects that can be partly ameliorated by feeding a high protein diet. ${ }^{9} 10$

$C$ reactive protein (CRP) is an acute phase protein that is present in very low concentrations in the serum of healthy subjects, but increases considerably and rapidly in response to an inflammatory stimulus. ${ }^{11}$ It is commonly used as a screening test to detect bacterial infection, ${ }^{12} 13$ and has been used to monitor the clinical response to treatment in patients with ulcerative colitis, ${ }^{14}$ a disease that shares many clinical and pathological similarities with shigellosis.

Prealbumin, like CRP, is a serum protein with a short half life of about two days. ${ }^{15}$ Unlike CRP, serum concentrations of prealbumin are responsive to nutrient, and especially to energy, intake. ${ }^{1617}$ Concentrations of prealbumin decline during acute infection, especially in association with anorexia, and usually rise after termination of the inflammatory process and renewed feeding.

As a measure of the systemic response to Shigella spp infection, CRP and prealbumin concentrations were determined in 39 adults acutely ill with shigellosis, and were compared with concentrations in 10 patients with diarrhoea caused by Vibrio cholerae serotype 01 .

\section{Methods}

\section{Study patients}

This study was conducted at the Diarrhoea Treatment Centre of the International Centre for Diarrhoeal Disease Research, Bangladesh (ICDDR,B). Patients included in this study were participating in a clinical trial comparing the efficacy of short course (one or two dose) ciprofloxacin treatment of Shigella spp infection with a standard five day, 10 dose regimen. ${ }^{18}$ The enrolment criteria for entry into the clinical trial have been reported earlier. ${ }^{18}$ Briefly, all patients enrolled in the study were men, between 18-60 years of age, had symptoms of dysentery for $<96$ hours, and had Shigella spp isolated from a stool or rectal swab sample obtained on admission to the study. All patients included in the study stayed in hospital for six days, and clinical outcomes were evaluated using predetermined criteria. ${ }^{18}$ Treatment was considered to have failed, if on study day 5 patients had more than six stools, one or more watery or dysenteric stools, or were febrile (oral temperature $>37 \cdot 8^{\circ} \mathrm{C}$ ). In addition, treatment was also considered to have failed in patients who had no improvement in their symptoms on 
study day 3. Treatment was considered to have been successful, if on study day 5 a patient had $\leqslant$ six total stools, no watery or dysenteric stools, and was afebrile.

Serum CRP and prealbumin concentrations were determined on $39(33 \%)$ of the 118 patients enrolled in the original study. These 39 patients included 10 patients who were infected with $S$ dysenteriae type 1 and in whom treatment was successful; 10 patients infected with $S$ dysenteriae type 1 in whom treatment failed; and 19 patients who were infected with Shigella spp other than $S$ dysenteriae type 1 and in whom treatment was successful. CRP and prealbumin concentrations were also measured in 10 patients who had diarrhoea caused by $V$ cholerae serotype 01 .

Nine of 10 patients infected with $S$ dysenteriae type 1 who failed treatment had received short course (single or two dose) ciprofloxacin therapy. Seven of these nine patients ultimately received five days of treatment with ciprofloxacin starting on study day 4 (three patients); study day 5 (one patient); and study day 6 (three patients). Six of 10 patients who were infected with $S$ dysenteriae type 1 and in whom treatment was clinically successful received short course therapy, and only one (because of failure of eradication of Shigella spp from stool) patient subsequently received a full five day course of ciprofloxacin beginning on study day 4 . Of 19 patients infected with Shigella spp other than $S$ dysenteriae type 1, 15 received short course treatment, none failed treatment, and none required antimicrobial treatment in addition to the short course treatment they had initially received.

\section{Study samples}

For patients infected with Shigella spp, blood samples for determination of serum CRP and prealbumin concentrations were obtained on four occasions: on admission to the study, on study days 3 and 5, and at a follow up visit approximately seven days after discharge from the hospital (14 days after admission). Blood samples were obtained from the $V$ cholerae infected patients on two occasions: on admission to the study and at a follow up visit approximately 10 days after admission.

\section{Laboratory methods}

For determination of CRP and prealbumin concentrations blood was collected into sterile tubes, kept at room temperature for an hour, and then centrifuged at 4000 revolutions per minute for 10 minutes. The serum was separated and stored at $-70^{\circ} \mathrm{C}$ until the assays were performed. For determination of CRP concentrations a turbidimetry technique using a Cobas-Bio discrete analyser (HoffmannLa Roche, Basle, Switzerland) and monospecific rabbit antihuman CRP immunoglobulin (Dakopatts, Glostrup, Denmark) were used. For determination of prealbumin concentrations a single radial immunodiffusion technique using plates containing monospecific antisera was used (Hoechst-Behring, Marburg, Germany). The lowest limit of detection for CRP using this method was $4.8 \mathrm{mg} / \mathrm{l}$ and for prealbumin $2.5 \mathrm{mg} / \mathrm{dl}$ in our laboratory. CRP values less than $4 \cdot 8$ were recorded as 0 .

\section{Statistical methods}

Data were entered into a personal computer using StatPac Gold (version 3.2, Walonick Associates, Minneapolis, $\mathrm{MN}$ ); and were analysed with Statistical Package for Social Sciences, $\mathrm{PC}^{+}$version 4.0 (SPSS, Chicago, IL) and Epi Info version 5.0 (USD, Stone Mountain, GA). Differences in means between the four groups were tested for significance using the analysis of variance (ANOVA) test, or the Kruskal-Wallis test if the findings were not normally distributed. When differences between the groups were significant on the ANOVA test, differences between individual groups were tested for significance using Scheffe's procedure. If the Kruskal-Wallis test was significant, individual groups were then compared using the Mann-Whitney $U$ test. Differences in categorical variables were tested for significance using the $\chi^{2}$ test, or Fisher's exact test if the predicted size of any cell was five or less. Sensitivity, specificity, predictive value of a positive test, and predictive value of a negative test were determined using standard methods. ${ }^{19}$ The values used for determining sensitivity and specificity were selected by first drawing receiver operator curves, and then

TABLE I Admission characteristics of the four patient groups

\begin{tabular}{|c|c|c|c|c|}
\hline \multirow[b]{2}{*}{ Characteristic } & \multicolumn{4}{|l|}{ Patient group } \\
\hline & $\begin{array}{l}S \text { dysenteriae type } 1 \\
\text { treatment successful } \\
(n=10)\end{array}$ & $\begin{array}{l}\text { S dysenteriae type } 1 \\
\text { treatment failed } \\
(n=10)\end{array}$ & $\begin{array}{l}\text { Other Shigella spp } \\
\text { treatment successful } \\
(n=19)\end{array}$ & $\begin{array}{l}\mathrm{V} \text { cholerae } \\
01 \\
(n=10)\end{array}$ \\
\hline Age $(y)^{\star}$ & $27(5)$ & $30(9)$ & $32(9)$ & $38(8)$ \\
\hline Duration of illness $(\mathrm{h})$ (median, range) $\dagger$ & $57(25-72)$ & $67(34-72)$ & $42(6-86)$ & $14(9-31)$ \\
\hline Temperature $>37.8^{\circ} \mathrm{C}(\mathrm{n})(\%) \ddagger$ & $3(30)$ & $5(50)$ & $8(42)$ & 0 \\
\hline Weight (kg) & $50(9)$ & $52(7)$ & $49(8)$ & $45(8)$ \\
\hline Moderate or severe dehydration (n) (\%) $\$$ & 0 & 0 & 0 & $10(100)$ \\
\hline \multicolumn{5}{|l|}{ Other enteric pathogens $(n)(\%)$} \\
\hline Salmonella spp & 0 & 0 & $1(5)$ & 0 \\
\hline Aeromonas spp & $2(18)$ & 0 & $1(5)$ & 0 \\
\hline Admission PCV \% & $43(4)$ & $44(6)$ & $45(4)$ & $60(4)$ \\
\hline Admission blood leucocyte count $\times 10^{2} / \mathrm{mm}^{3}$ & $104(39)$ & $111(38)$ & $113(25)$ & Not done \\
\hline \multicolumn{5}{|l|}{ Stool microscopic examination $(n)(\%)$} \\
\hline $\begin{array}{l}>50 \text { leucocytes/high powered microscopic field } \S \\
>50 \text { erythrocytes/high powered microscopic field } \$\end{array}$ & $\begin{array}{l}10(100) \\
9(90)\end{array}$ & $\begin{array}{l}10(100) \\
10(100)\end{array}$ & $\begin{array}{l}18(95) \\
17(90)\end{array}$ & $\begin{array}{l}1(10) \\
0\end{array}$ \\
\hline
\end{tabular}

Values are mean (SD). ${ }^{\star} \mathrm{p}=0.035$ by ANOVA. Group 1 compared with group $4, \mathrm{p}<0.05$ by Scheffe's procedure. $t \mathrm{p}<0.001$ by Kruskal-Wallis test. Group 1,2 , and 3 compared with group $4, \mathrm{p}<0.001$ by Mann-Whitney U test. $\ddagger \mathrm{p}=0.02$ by Fisher's exact test, all Shigella spp compared with $V$ cholerae. $\$ \mathrm{p}<0.001$ by Fisher's exact test, all Shigella spp compared with $V$ cholerae. $\| \mathrm{p}<0.001$ by AVOVA. Group 1,2 , and 3 compared with group $4, \mathrm{p}<0.05$ by Scheffe's procedure. 
TABLE II Sensitivity, specificity, and positive and negative predictive values of selected variables for determining failure of antimicrobial treatment in patients with shigellosis

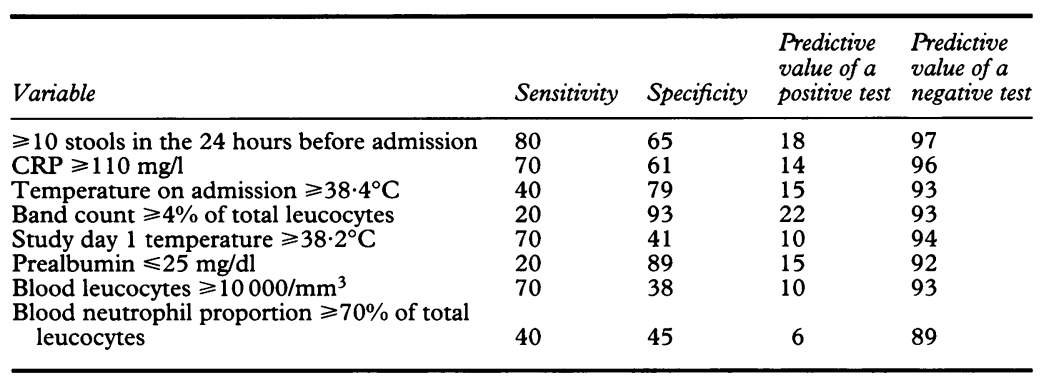

Values are percentages.

selecting the test value that gave the largest sum when sensitivity and specificity were added. For calculating predictive values, the results from the sample population were extrapolated to the total study population, and the calculations performed using these extrapolated values.

This study was approved by the scientific and ethical review committees of the ICDDR,B.

\section{Results}

Table I shows the characteristics of the patients in the four groups on admission to the study.

All 10 patients with cholera, but none of the patients with shigellosis, were moderately or severely dehydrated. Patients with cholera had a significantly shorter illness duration, a higher blood packed cell volume, fewer erythrocytes and leucocytes in their stools, and less often had fever than did patients infected with Shigella spp.

Figure 1 shows the median serum CRP concentrations by patient group and study day. Patients infected with $V$ cholerae had significantly $(\mathrm{p}<0 \cdot 01)$ lower admission CRP concentrations than did the three groups of patients infected with Shigella spp. In all three groups of patients infected with Shigella spp, median CRP concentrations were significantly higher on admission and study day 3 than when

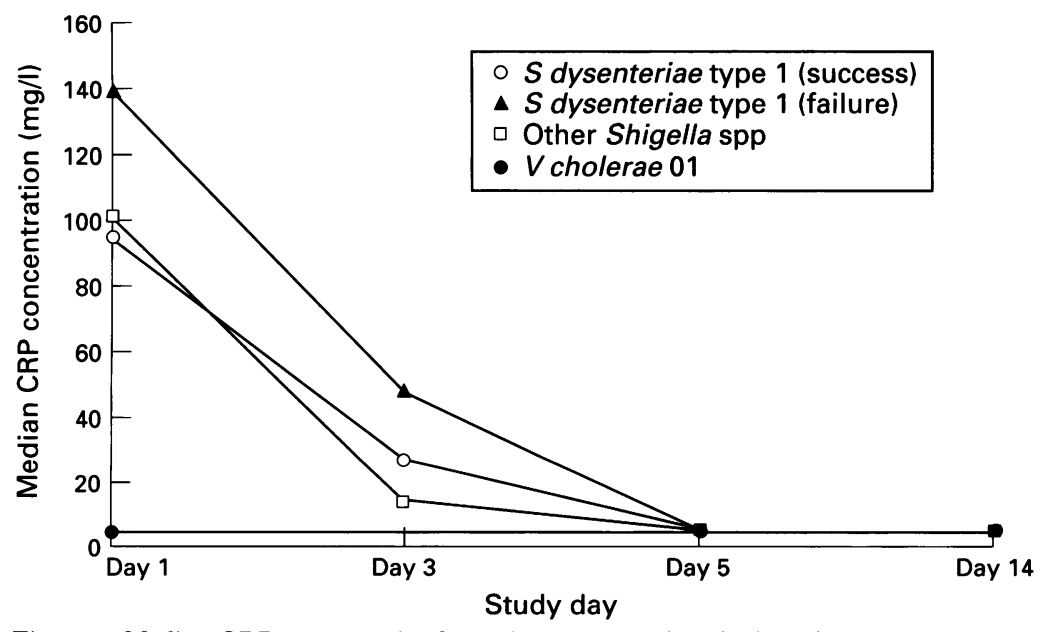

Figure 1: Median CRP concentration by patient group and study day. Admission CRP concentrations were significantly $(p<0.05)$ lower in the cholera group when compared with each of the other three groups. CRP concentrations were significantly higher on study days 3 and $5(p<0.05)$ in $S$ dysenteriae type 1 infected patients in whom treatment subsequently failed than in the patients infected with Shigella spp other than $\mathrm{S}$ dysenteriae type 1. measured on study day 5 and at a follow up visit. On admission median CRP concentrations were higher in $S$ dysenteriae type 1 infected patients in whom initial treatment failed, than in the other two groups of patients infected with Shigella spp. Of the 10 patients infected with $V$ cholerae, three had CRP concentrations above $4.8 \mathrm{mg} / \mathrm{l}$ on admission, with the highest being $70.4 \mathrm{mg} / \mathrm{l}$. At follow up, all 10 patients had a CRP concentration less than $4 \cdot 8 \mathrm{mg} / \mathrm{l}$.

Figure 2 shows the median serum prealbumin concentrations by patient group and study. On admission, the median prealbumin concentration in the 10 patients infected with $V$ cholerae was significantly $(p<0.05)$ higher than in either of the two groups of patients infected with $S$ dysenteriae type 1 . When compared with admission concentrations, median prealbumin concentrations were significantly higher on study days 3 and 5, and at follow up, in all three groups of patients infected with Shigella spp. Median prealbumin concentrations were within the normal range in all three Shigella spp infected groups on study day 5 and at the time of follow up examination. Median concentrations of prealbumin in $V$ cholerae infected patients did not differ between admission and follow up.

Table II shows the utility of different measures in predicting clinical outcome. A CRP concentration of $\geqslant 110 \mathrm{mg} / \mathrm{l}$ had a sensitivity of $70 \%$ and a specificity of $61 \%$ in identifying patients in whom treatment would ultimately fail. This CRP concentration was a better predictor of outcome than total blood leucocyte count, total premature leucocytes, maximum temperature on the first study day, and admission prealbumin concentration. A history of 10 or more stools in the 24 hours before admission was, however, as sensitive and specific as CRP in identifying patients in whom treatment would fail. Because failure of antimicrobial treatment was comparatively uncommon, the positive predictive value of a serum CRP concentration $\geqslant 110 \mathrm{mg} / \mathrm{l}$ was only $14 \%$.

\section{Discussion}

In comparison with patients infected with $V$ cholerae, patients infected with Shigella spp had considerably increased serum concentrations of CRP, and considerably diminished serum concentrations of prealbumin. These findings are consistent with the pathogenesis of $V$ cholerae and Shigella spp infections; the first is largely confined to the intestinal lumen, and the second invades the colonic mucosa. That patients infected with $S$ dysenteriae type 1 had higher concentrations of CRP than patients infected with other Shigella spp is also consistent with both clinical and experimental studies that have shown that of all the Shigella spp serotype, infection with $S$ dysenteriae type 1 elicits the most severe inflammation. ${ }^{20}$

Among patients infected with Shigella spp, the highest CRP concentrations were seen in patients in whom initial treatment failed. Serum CRP concentrations were a better 


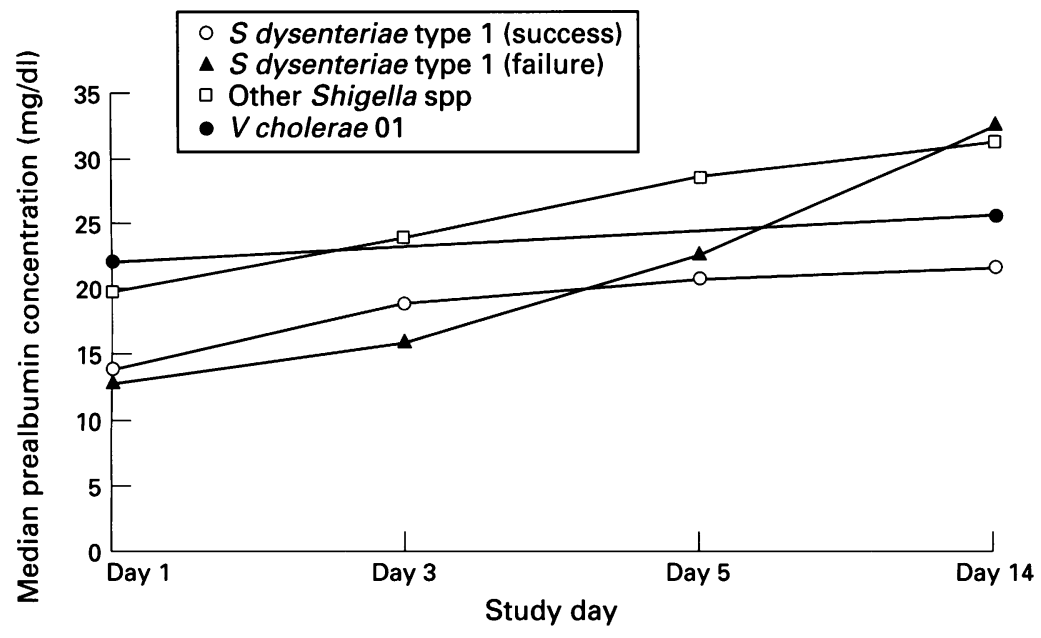

Figure 2: Median

prealbumin concentrations by patient group and study day. Admission prealbumin concentrations were significantly $(p<0.05)$ higher in patients infected with $\mathrm{V}$ cholerae than in both groups of patients infected with $\mathrm{S}$ dysenteriae type 1. Patients infected with Shigella spp other than $\mathrm{S}$ dysenteriae type 1 had significantly higher $(p<0.05)$ prealbumin concentrations on day 3,5 , and at follow up visit than did patients infected with $S$ dysenteriae type 1 in whom treatment was successful. At follow up visit patients infected with $S$ dysenteriae type 1 in whom treatment was successful had significantly $(p<0.05)$ lower

prealbumin concentrations than did patients infected with S dysenteriae type 1 in whom initial treatment failed. Seven of 10

$\mathrm{S}$ dysenteriae type 1 patients in whom initial treatment failed received alternate treatment before returning for their follow up visit. predictor of outcome than total blood leucocyte count, maximum fever on the first hospital day, or the blood neutrophil proportion of total leucocytes.

Three of $10 \mathrm{~V}$ cholerae infected patients had increased CRP concentrations on admission. Although $V$ cholerae is characteristically thought not to elicit an inflammatory response in the gut, studies have found that peripheral blood leucocyte counts are increased, and that some cholera patients are febrile during their illness. ${ }^{21} \mathrm{~A}$ previous study of 22 patients also showed increased CRP concentration in patients with cholera. ${ }^{22}$ The mechanism by which $V$ cholerae infection elicits this increase in CRP concentrations remains unknown.

The diminished prealbumin concentrations in patients with shigellosis in this study are consistent with previous epidemiological findings that dysentery has a profound effect on nutrition and growth, ${ }^{9}$ and could be the result of a number of different pathological processes. Firstly, anorexia is a common feature of shigellosis and prealbumin concentrations are known to decline rapidly after energy or protein deprivation. Secondly, the acute inflammatory response is known to down regulate synthesis of prealbumin and albumin. Lastly, patients with shigellosis have been shown to have a protein losing enteropathy, ${ }^{23}$ and the diminished prealbumin concentrations may in part be caused by the loss of this protein into the gut. During hospital course prealbumin concentrations in $S$ dysenteriae type 1 infected patients, irrespective of outcome, were lower than in patients infected with other Shigella spp. $S$ dysenteriae type 1 infection is known to cause more severe colitis and greater gut protein loss than infections caused by other Shigella spp. ${ }^{23}$ The return of prealbumin concentrations to normal when patients returned for a follow up visit suggests that with appropriate antimicrobial treatment and nutritional support, such as these patients received, the impact of shigellosis on nutrition can be ameliorated. ${ }^{78}$ In contrast with the patients with shigellosis, prealbumin concentrations were normal in the patients with cholera. This finding is consistent with the finding that watery diarrhoea has less of an impact on nutritional status than dysentery. ${ }^{9}$

The findings of this study re-emphasise the need to consider, and treat, shigellosis as a clinical entity that is different from watery diarrhoea caused by $V$ cholerae or other enteropathogens. In contrast with cholera, patients with shigellosis have a systemic disease that persists after rehydration. While fluid replacement in cholera patients is the crucial element in their treatment, patients with shigellosis clearly require additional nutritional support, and perhaps control of the inflammatory response, for early return to health.

This research was supported by the International Centre for Diarrhoeal Disease Research, Bangladesh (ICDDR,B). The ICDDR,B is supported by the countries and agencies that share its concern for the health problems of developing countries. Current donors include: the Governments of Australia, Bangladesh, Belgium, Canada, China, Denmark, Germany, Japan, the Netherlands, Norway, Republic of Korea, Saudi Arabia, Sweden, Switzerland, the United Kingdom, and the Arabia, Sweden, Switzerland, the United Kingdom, and the (UNICEF), and the United Nations Development Programme (UNDP).

We thank Mr Humayun Kabir for assistance with data entry onto computer, Dr F C Patra for providing serum samples from patients with cholera, and the doctors, nurses, and staff of the diarrhoea treatment centre of the International Centre for Diarrhoeal Disease Research, Bangladesh for assisting with the care of patients enrolled in the study.

1 Speelman P, Kabir I, Islam M. Distribution and spread of colonic lesions in shigellosis: a colonoscopic study. F Infect Dis 1984; 150: 899-903.

2 Anand BS, Malhotra V, Bhattacharya SK, Datta P, Datta D, Sen D, et al. Rectal histology in acute bacillary dysentery. Gastroenterology 1986; 90: 654-60.

3 Mathan MM, Mathan VI. Ultrastructural pathology of the rectal mucosa in Shigella dysentery. Am $₹$ Pathol 1986; 123: 25-38.

4 Butler T, Dunn D, Dahms B, Islam M. Causes of death and the histopathologic findings in fatal shigellosis. Pediatr Infect Dis ₹ 1989; 8: 767-72

5 Butler T, Islam MR, Bardhan PK. The leukemoid reaction in shigellosis. Am $\mathcal{f}$ Dis Child 1984; 138: 162-5.

6 Bennish ML, Harris JR, Wojtyniak BJ, Struelens M. Death in shigellosis: incidence and risk factors in hospitalized patients. F Infect Dis 1990; 161: 500-6.

7 Black RE, Brown KH, Becker S. Effects of diarrhea associated with specific enteropathogens on the growth of children in rural Bangladesh. Pediatrics 1984; 73: 799-805.

8 Henry FJ, Alam N, Aziz KMS, Rahaman MM. Dysentery, not watery diarrhoea, is associated with stunting in Bangladeshi children. Human Nutrition: Clinical Nutrition 1987; 41C: $243-9$.

9 Kabir I, Butler T, Underwood LE, Rahman MM. Effects of a protein-rich diet during convalescence from shigellosis on catch-up growth, serum proteins, and insulin-like growth factor-1. Pediatr Res 1992; 32: 689-92.

10 Kabir I, Malek MA, Mazumder RN, Rahman MM, Mahalanabis D. Rapid catch-up growth of children fed a high-protein diet during convalescence from shigellosis. Am F Clin Nutr 1993; 57: 441-5.

11 Kushner I, Gewurz H, Benson MD. C-reactive protein and the acute phase response. $\mathcal{f}$ Lab Clin Med 1981; 97: 739-49.

12 Bennish M, Beem MO, Ormiste V. C-reactive protein and zeta sedimentation ratio as indicators of bacteremia in pediatric patients. $\mathcal{F}$ Pediatr 1984; 104: 729-32.

13 Saez-Llorens X, Lagrutta F. The acute phase host reaction during bacterial infection and its clinical impact in children. Pediatr Infect Dis $\mathcal{F}$ 1993; 12: 83-7.

14 Buckell NA, Lennard-Jones JE, Hernandez MA, Kohn J, Riches PG, Wadsworth J. Measurement of serum proteins during attacks of ulcerative colitis as a guide to patient management. Gut 1979; 20: 22-7.

15 Shetty PS, Watrasiewicz KE, Jung RT, James WPT. Rapidturnover transport proteins: an index of subclinical protein-energy malnutrition. Lancet 1979; ii: $230-2$.

16 Brose L. Prealbumin as a marker of nutrition status. $\mathcal{f}$ Burm Care Rehabil 1990; 11: 372-5.

17 De Visscher M, De Nayer P. Measurement of prealbumin as index of protein-calorie malnutrition. Lancet 1972; ii: 106-8.

18 Bennish ML, Salam MA, Khan WA, Khan AM. Therapy of shigellosis: III. Comparison of one or two dose ciprofloxacin with standard five day therapy. Ann Intern Med 1992; 117: 727-34.

19 Altman DG. Practical statistics for medical research. London: Chapman and Hall, 1991: 409-15.

20 Bennish ML. Potentially lethal complications of shigellosis. Rev Infect Dis 1991; 13 (suppl 4): S319-24.

21 Greenough WB, III, Gordon RS, Rosenberg IS, Davies BI Tetracycline in the treatment of cholera. Lancet 1964; $\mathrm{i}$ : 355-7.

22 Barua D, Sack RB. C-reactive protein in cholera: a preliminary report. Bull Calcutta Sch Trop Med 1963; 11: 86-7.

23 Bennish ML, Salam MA, Wahed MA. Enteric protein loss during shigellosis. Am f Gastroenterol 1993; 88: 53-7. 